\title{
IN SITU AND EX SITU TARGET STRENGTH MEASUREMENT OF MESOPELAGIC LANTERNFISH, DIAPHUS THETA (FAMILY MYCTOPHIDAE)
}

Kouichi Sawada

National Research Institute of Fisheries Engineering, Fisheries Research Agency, 7620-7 Hasaki, Kamisu, Ibaraki, 314-0408, Japan., ksawada@fra.affrc.go.jp

Kazuhisa Uchikawa Japan Sea National Research Institute, Fisheries Research Agency, 1-5939- 22 Suido-cho, Chuo-ku, Niigata, 951-8121, Japan.

Tomohiko Matsuura

Tokyo University of Marine Science and Technology, 4-5-7 Konan, Minatoku, Tokyo, 108-8477, Japan.

Hiroya Sugisaki

National Research Institute of Fisheries Science, Fisheries Research Agency, 2-12-4 Fukuura, Kanazawa-ku, Yokohama, 236-8648, Japan.

Kazuo Amakasu

Tokyo University of Marine Science and Technology, 4-5-7 Konan, Minatoku, Tokyo, 108-8477, Japan.

See next page for additional authors

Follow this and additional works at: https://jmstt.ntou.edu.tw/journal

Part of the Aquaculture and Fisheries Commons

\section{Recommended Citation}

Sawada, Kouichi; Uchikawa, Kazuhisa; Matsuura, Tomohiko; Sugisaki, Hiroya; Amakasu, Kazuo; and Abe, Koki (2011) "IN SITU AND EX SITU TARGET STRENGTH MEASUREMENT OF MESOPELAGIC LANTERNFISH, DIAPHUS THETA (FAMILY MYCTOPHIDAE)," Journal of Marine Science and Technology. Vol. 19: Iss. 3, Article 10.

DOI: 10.51400/2709-6998.2196

Available at: https://jmstt.ntou.edu.tw/journal/vol19/iss3/10

This Research Article is brought to you for free and open access by Journal of Marine Science and Technology. It has been accepted for inclusion in Journal of Marine Science and Technology by an authorized editor of Journal of Marine Science and Technology. 
IN SITU AND EX SITU TARGET STRENGTH MEASUREMENT OF MESOPELAGIC LANTERNFISH, DIAPHUS THETA (FAMILY MYCTOPHIDAE)

Acknowledgements

We thank associate professor, Kazuhiko Anraku (Kagoshima university), Tomoki Ogawa, and Junya Shigeno for their various field assistance. We thank crew of RV "Wakataka-Maru" for their dedicated assistance. Anonymous referees and the guest editor, Dr. Masahiko Furusawa greatly improved this manuscript.

\section{Authors}

Kouichi Sawada, Kazuhisa Uchikawa, Tomohiko Matsuura, Hiroya Sugisaki, Kazuo Amakasu, and Koki Abe 


\title{
IN SITU AND EX SITU TARGET STRENGTH MEASUREMENT OF MESOPELAGIC LANTERNFISH, DIAPHUS THETA (FAMILY MYCTOPHIDAE)
}

\author{
Kouichi Sawada*, Kazuhisa Uchikawa**, Tomohiko Matsuura***, \\ Hiroya Sugisaki****, Kazuo Amakasu***, and Koki Abe*
}

Key words: in situ target strength, Diaphus theta, J-QUEST $\chi$, swimbladder, spheroid model.

\begin{abstract}
Acoustic target strengths (TS) of myctophid fish Diaphus theta were measured in situ at $70 \mathrm{kHz}$ off the east coast of Hokkaido by tethering an acoustic-optical system (the Japanese Quantitative Echosounder and Stereo-video Camera System or J-QUEST $\chi$ ) at a depth of $150 \mathrm{~m}$ from a research vessel. Fish length distributions were obtained from daytime hauls taken with a frame trawl after the TS measurement. Measured average TS $(<T S>)$ and a standard length $(S L)$ in $\mathrm{cm}$ gave the empirical length - average TS relationship, $\langle T S\rangle=20 \log S L$ 70.6 , assuming that the linear TS is proportional to the square of the SL. A laboratory TS measurement and theoretical modeling of $D$. theta support the estimated length - average TS relationship.
\end{abstract}

\section{INTRODUCTION}

Myctophid fishes are one of the most abundant and widespread mesopelagic fish taxa in the world ocean, except for the Arctic Ocean. They are a key component of the oceanic ecosystems, where they generally prey on crustacean zooplankton and are consumed by marine birds, marine mammals, and fish $[4,11]$.

$D$. theta is widely distributed and is one of the most domi-

Paper submitted 06/22/10; revised 09/08/10; accepted 09/14/10. Author for correspondence: Kouichi Sawada (e-mail: ksawada@fra.affrc.go.jp).

*National Research Institute of Fisheries Engineering, Fisheries Research Agency, 7620-7 Hasaki, Kamisu, Ibaraki, 314-0408, Japan.

**Japan Sea National Research Institute, Fisheries Research Agency, 1-593922 Suido-cho, Chuo-ku, Niigata, 951-8121, Japan.

***Tokyo University of Marine Science and Technology, 4-5-7 Konan, Minatoku, Tokyo, 108-8477, Japan.

****National Research Institute of Fisheries Science, Fisheries Research Agency, 2-12-4 Fukuura, Kanazawa-ku, Yokohama, 236-8648, Japan. nant myctophids in the subarctic North Pacific Ocean ([2]). D. theta undertakes diel vertical migration [26], and is often consumed by fish and marine mammals such as walleye pollock, Theragra chalcogramma [27] and Dall's porpoise, Phocoenoides dalli [16]. Thus, D. theta plays an important role in transferring organic material from lower to higher trophic levels in the region. To understand the ecological function of this species, reliable biomass estimates are needed.

Acoustic methods have become important and reliable methods for fisheries resource survey [10]. It is considered as an objective method and can assess small-scale spatial and temporal heterogeneity effectively. Recently, an acoustic survey of $D$. theta was conducted to estimate its density off the eastern Hokkaido, Japan [29]. To estimate fish density from volume scattering, the average target strength must be known within the study area $[6,14]$. A model based TS [30] was used for the density estimation of D. theta in that study [29]. For the precise estimation of TS, swimbladder condition is very important, as it reflects $90 \%$ or more of the backscattered energy [5].

It has been reported that $D$. theta smaller than $87 \mathrm{~mm}$ in standard length $(S L)$ had a swimbladder and that swimbladderless ones appeared when the $S L$ became larger than $78 \mathrm{~mm}$ [31]. It has been also shown that swimbladder length of $D$. theta increased with $S L$ and showed the positive allometry [30]. The relationship between standard length (SL) and average $\mathrm{TS}(\langle T S\rangle)$ at $38 \mathrm{kHz}$ has been shown as $\langle T S\rangle=$ 11.8log $S L-63.5$ by Yasuma et al. [31] and revised as $\langle T S\rangle=$ $18.5 \log S L-71.7$ by Yasuma et al. [30]. Their results came from the theoretical calculations (vacant prolate-spheroid modal series model or PSM, [9]) based on the swimbladder morphological parameters (major and minor diameters) which were obtained from soft X-ray images of the swimbladder's shape. They assumed fish tilt-angle distribution as normal distribution with an average of $-5^{\circ}$ (negative sign indicates head down, positive head up) and a standard deviation of $15^{\circ}$ in the former paper and with an average of $0^{\circ}$ and a standard deviation of $15^{\circ}$ in the latter paper. In the small $L / \lambda$ 
region, where $L$ is a length of fish and $\lambda$ is a wavelength, tilt-angle distribution is not a major source of TS variation, but it is an essential in the large $L / \lambda$ region. It is necessary to measure tilt-angle distribution in situ in order to confirm their model. There is another concern about the changes of swimbladder shape under pressure. In the work of Yasuma et al. [30], fishes were sampled at depths ranging $50-300 \mathrm{~m}$ in the nighttime and the live ones were acclimatized for one to three hours in a small tank. They were frozen immediately after the acclimatization. According to Watanabe et al. [26], juveniles and adults of $D$. theta undergo a diel vertical migration between layers 20-100 $\mathrm{m}$ in the nighttime and 300-500 $\mathrm{m}$ deep in the daytime. This corresponds pressure change of 2-4.8 MPa or 20-40 atm in a day. Swimbladder shape at shallower depths may be different from the one at deeper depths, because of the difference of pressure. Horne et al. [12] examined the effect of the pressure change to target strength by taking dorsal and lateral radiographs of three juvenile walleye pollock in a pressure chamber to image swimbladders from ambient to a maximum of $0.49 \mathrm{MPa}$ corresponding to $5 \mathrm{~atm}$. At most $4 \mathrm{~dB}$ decreases of TS were indicated over the 0.5 MPa experimental pressure range by their theoretical calculation based on the swimbladder shapes. In this meaning, in situ TS measurement for fish aggregation with different length distribution is essential to derive a reliable $S L$ vs. $T S$ model as the measured TS is considered to reflect the tiltangle distribution and swimbladder conditions. D. theta, however, is known to distribute at mesopelagic layer in the daytime [26]. Generally, it is difficult to get precise TS when the spatial density of fish is high or when a fish school is deep from a transducer because of overlapping echoes [18].

National Research Institute of Fisheries Engineering has developed an acoustic-optical composite system (Japanese quantitative echosounder and stereo-video camera system, J-QUEST) which is designed to be deployed from a drifting research vessel to measure fish TS, fish length, and tilt-angle distributions from above or within a school $[20,21]$. The maximum working depth of the former system, J-QUEST, was improved up to $500 \mathrm{~m}$ and the improved system was named as J-QUEST $\chi$ [22]. The above issues related to the in situ TS measurement of $D$. theta can be overcome by using J-QUEST $\chi$.

The purpose of this study is to propose a reliable length $(S L)$ - average $\operatorname{TS}(<T S>)$ relationship of $D$. theta at $70 \mathrm{kHz}$ by the trawl sampling and in situ TS measurements using J-QUEST $\chi$. Through the in situ TS calculations, the effects of upper TS threshold levels, which were used to reduce the unwanted large echoes other than $D$. theta, were explored. Proposed relationship is confirmed by the theoretical model calculations based on the swimbladder shape of D. theta, assuming several tilt-angle distributions. The validity of the model calculation is confirmed by comparing model calculations with ex situ TS measurement in a tank. Predicted $S L$ vs $\langle T S>$ relationships based on the model calculations at $38 \mathrm{kHz}$ are also compared with the past data [30].
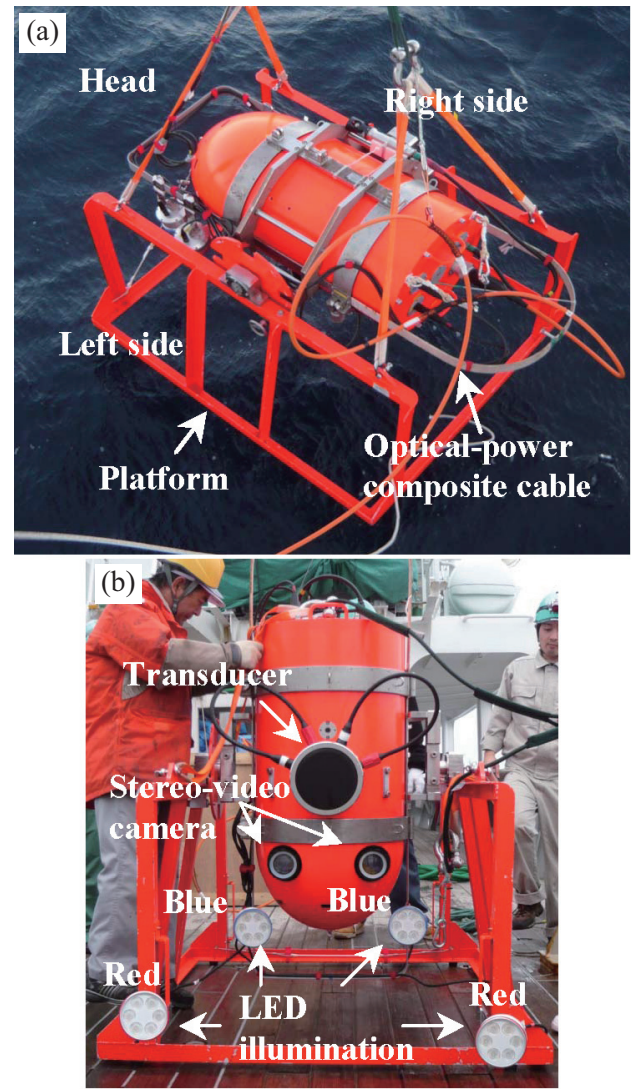

Fig. 1. Optical and acoustical system, J-QUEST $\chi$. (a) Down looking mode and (b) side looking mode.

\section{MATERIALS AND METHODS}

\section{Acoustic-Optical System (J-QUEST $\chi$ )}

The maximum working depth of the former system, J-QUEST, was increased from $300 \mathrm{~m}$ up to $500 \mathrm{~m}$ by replacing the transducer, lenses of the stereo camera, underwater cable, and transformers of the power supply unit. The improved system was named as J-QUEST $\chi$ [22] (Fig. 1). Halmeic lights were replaced by LED illuminations (red and blue color, 12W). A nine-axes (acceleration, angular acceleration, and magnetic direction for $\mathrm{x}, \mathrm{y}$, and $\mathrm{z}$ axes) motion sensor (AHRS-400MA, Crossbow Ltd.) was installed in a pressure cage. A CTD (ASTD-RS, JFE Advantec Ltd.) sensor was connected to the pressure cage.

Along with the improvement of the working depth, a 70 $\mathrm{kHz}$ split-beam transducer was newly developed [19]. The transducer consists of 148 elements and they are grouped in separate 8 channels. Combinations of each channel form phase beams and narrow or wide beam with beam width of $8.4^{\circ}$ and $11.8^{\circ}$, respectively.

Downward-looking (Fig. 1(a)) or side-looking mode (Fig. 1(b)) can be selected before the deployment by rotating the pressure case on a newly manufactured platform. The platform with the pressure cage (underwater unit) is tethered and 


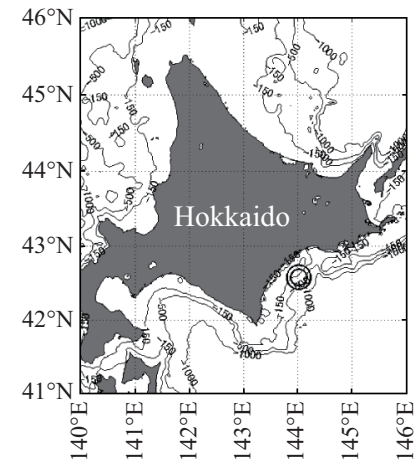

(a)

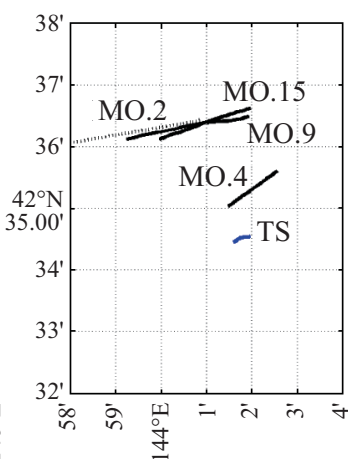

(b)
Fig. 2. (a) Survey site (double circles). (b) Expanded survey site shown in (a) as the double circle. TS measurement (abbreviated as TS in this figure) and trawling (MO.2, 4, 9, 15, see Table 1) are indicated. MO.4, 9, 15 were conducted in the daytime and MO.2 was conducted in the nighttime.

deployed from a vessel. This method makes it easy to deploy and haul up the J-QUEST $\chi$ at sea.

The stereo-video camera has a field of view of $15^{\circ}$. The details of the stereo-video camera was described by Takahashi et al. [24] and measurement accuracy was reported by Takahashi et al.[23].

A $530 \mathrm{~m}$ optical-power composite cable (diameter $15 \mathrm{~mm}$ ) connects the underwater unit and a deck unit. It has six silica optical fibers (single mode) and five of which are used for signal transmissions. Fiber-1 is used for the controls and data transmissions of LED illuminations, the stereo-video camera system, and the motion sensor. Fiber- 2 is used for the echosounder and the CTD sensor. Fiber-3 is used for external trigger signal to the LED illuminations. Fiber- 4 and 5 are used for the transmissions of video signals from the stereo-video camera. All the data is monitored and recorded in real-time on deck. AC250V power is provided through aluminum lines of the composite cable.

\section{Survey}

The survey was conducted on board Fisheries Research Agency (alleviated as FRA) ship Wakataka-maru (692 ton). After short scouting for dense aggregations of $D$. theta at the marginal of the shelf break off Hokkaido (Fig. 2, ca. 500-800 $\mathrm{m}$ deep), the vessel was drifted and echoes were collected for the distinct scattering layers as shown in Fig. 3 using shipboard echosounders (KFC3000, Sonic Ltd., frequency: $38 \mathrm{kHz}$, $120 \mathrm{kHz}$, pulse width: $1.2 \mathrm{~ms}$, beam width: $8.4^{\circ}$, ping rate: 4 $\mathrm{sec})$ and J-QUEST $\chi\left(70 \mathrm{kHz}, 0.6 \mathrm{~ms}, 11.8^{\circ}, 0.2 \mathrm{sec}\right)$. To investigate species and size compositions, net samplings were also carried out for 20 min using a frame trawl [17] (mouth opening: $5 \mathrm{~m}^{2}, 4 \mathrm{~mm}$ mesh, towing speed: $c a .3 \mathrm{kt}$, abbreviated as MOHT in this paper) after the echo data collection. A net recorder was attached to the depressor of the net to monitor the net depth during towing. After the confirmation that a large number of the samples consisted of $D$. theta, continuous observation started. As a series of observation, echo data col-

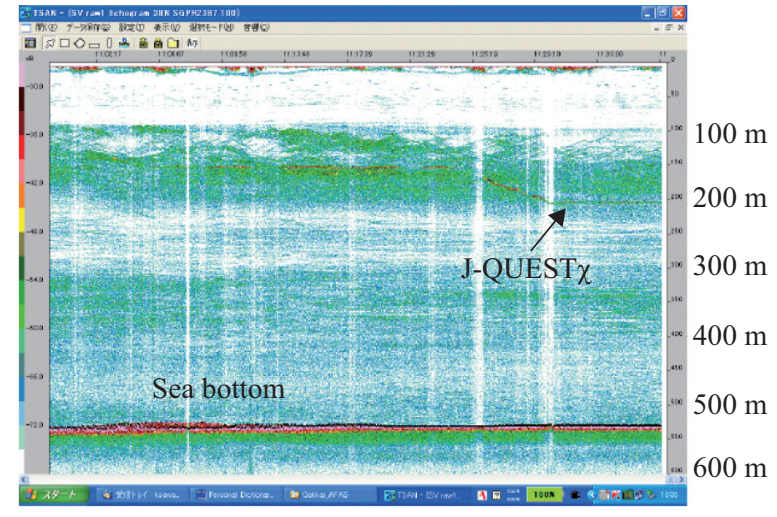

Fig. 3. Observed echogram (20log TVG) from the echosounder installed on vessel ( $38 \mathrm{kHz}, 1.2 \mathrm{~ms}$ ). Successive echoes from J-QUEST $\chi$ is shown in the figure.

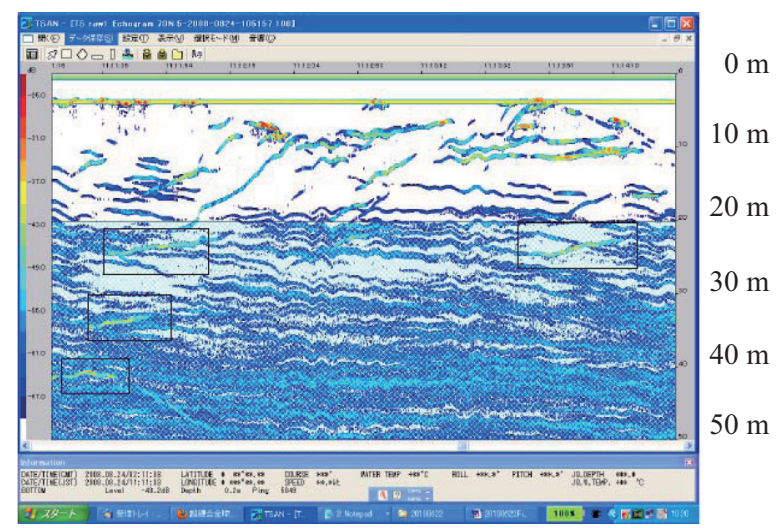

Fig. 4. Observed echogram (Aug 24, 2008, 11:11:15-11:14:30, 40log TVG) from J-QUEST $\chi$. Vertical range shown in the right hand side started from the transducer depth of J-QUEST $\chi$. Target strengths of the shaded area were estimated. Echoes surrounded by squares were considered to be other echoes than $D$. theta.

lection, CTD casts ( 7 casts), and net samplings (16 hauls) were carried out from 23 Aug, 2008 for 5 days.

\section{In situ TS Measurement}

The J-QUEST $\chi$ was deployed in the down-looking mode (Fig. 1(a)) at a depth of $150 \mathrm{~m}$ with a tethered standard sphere (tungsten-carbide, $38.1 \mathrm{~mm}$ diameter) $3.3 \mathrm{~m}$ below the transducer for the calibration purpose at operating depths.

Single echoes retuned from fishes were collected during 10:52-11:24 for 32 minutes on 24 Aug. 2008. Fig. 4 shows a part of the echogram observed by the J-QUEST $\chi$.

The echoes at the range between $20-50 \mathrm{~m}$ below the transducer of J-QUEST $\chi$ (which corresponds to 170-200 m from the surface and out of range of the stereo camera observation) were analyzed to avoid the effects of LED illumination to fish behavior (Fig. 4). Because lighting attracts squids and many pelagic fishes whereas myctophids fishes avoid bright illuminations. Actually we observed squids and adult walleye pollock on the stereo-video monitor and on the echogram 
Table. 1. Trawl sampling date, time, position, and depth.

\begin{tabular}{lccc}
\hline & \multicolumn{3}{c}{ Station } \\
\cline { 2 - 4 } & MO4 & MO9 & MO15 \\
\hline Date & Aug. 24, 2008 & Aug. 25, 2008 & Aug. 27, 2008 \\
Time & $14: 16-14: 36$ & $14: 43-15: 13$ & $14: 23-15: 00$ \\
Latitude & $42^{\circ} 35.06^{\prime} \mathrm{N}$ & $42^{\circ} 36.62^{\prime} \mathrm{N}$ & $42^{\circ} 36.49^{\prime} \mathrm{N}$ \\
Longitude & $144^{\circ} 01.53^{\prime} \mathrm{E}$ & $144^{\circ} 01.94^{\prime} \mathrm{E}$ & $144^{\circ} 01.93^{\prime} \mathrm{E}$ \\
Towing depth (m) & $190-200 \mathrm{~m}$ & $190 \mathrm{~m}$ & $200 \mathrm{~m}$ \\
\hline
\end{tabular}

under illumination. At least echoes of adult walleye pollock were relatively stronger than other echoes. In addition, one walleye pollock (adult, fork length $=37.5 \mathrm{~cm}$ ) was captured at MO.2 (see Fig. 2(b)) in the nighttime at a net depth of $190 \mathrm{~m}$.

To exclude other echoes than $D$. theta, the upper $20 \mathrm{~m}$ was excluded from the TS analysis and an upper threshold was applied to the TS analysis layer, as echoes of walleye pollock and squids might still remain in the layer. The upper TS threshold was determined by considering the TS pattern of the largest $D$. theta among 3 hauls (MO.4, 9, 15, see Table 1) with allowance of $3 \mathrm{~dB}$ (corresponding to $41 \%$ allowance in $S L$ ).

In the present study, a lower TS threshold was set $-70 \mathrm{~dB}$ and upper ones were changed from $-50 \mathrm{~dB}$ to $-43 \mathrm{~dB}$ at a $1 \mathrm{~dB}$ step. Average TS was determined by averaging TS values in linear domain at four different upper thresholds weighted by the number of echoes at each threshold. The determination of the upper threshold value of $-50 \mathrm{~dB}$ was elaborated in "5. Model calculations based on the swimbladder shape".

Target strengths of the specimen were calculated using a calibration procedure incorporating the reference target:

$$
T S=20 \log V+40 \log r+2 \alpha r-2 D-T R
$$

where $V(\mathrm{~V})$ is an echo amplitude, $r(\mathrm{~m})$ is a distance from the transducer to the target, $\alpha(\mathrm{dB} / \mathrm{m})$ is an absorption coefficient, $D(\mathrm{~dB})$ is a directivity of the transducer, and $T R(\mathrm{~dB})$ is a transmitting and receiving factor which is determined by the sphere calibration.

Cut-off angle of $2.5^{\circ}$ which corresponded to $1.1 \mathrm{~dB}$ for the two-way beam directivity correction ( $2 D$ in the equation) was applied for average TS calculations to minimize the directivity correction errors [25]. The details of the TS analysis procedure was given by Sawada et al. [20].

After the single echoes collection, a frame trawl was conducted at target depths of 190-200 m where single echoes were collected. It is well known that it is not easy to sample the same fish that have been observed by the acoustic instruments [14]. To investigate whether we can catch a representative sample of fish, another results from two trawls that were conducted in the similar time of the day, for the similar position, and the similar layer but different days were compared. Date, time, position, and towing depth for three MOHT net samplings were summarized in Table 1 (see also Fig. 2).

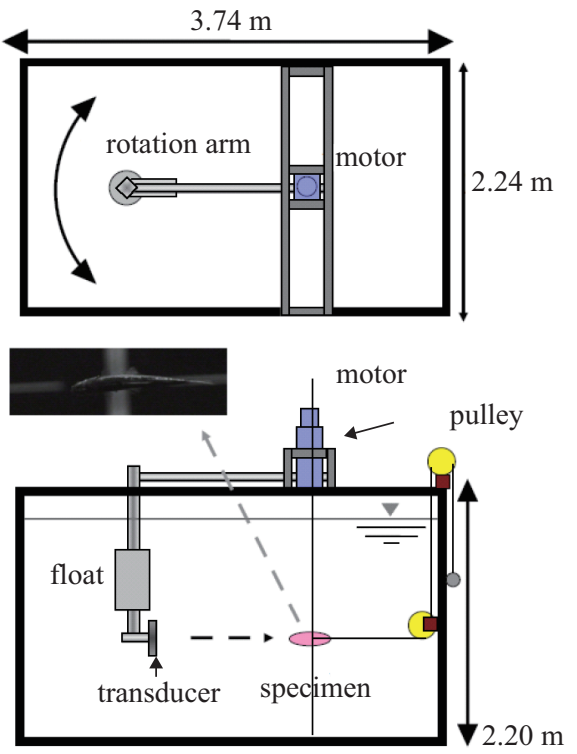

Fig. 5. Experimental tank with the rotating transducer. The upper panel is the top and the lower is the side view of the tank. A specimen is located as its dorsal aspect faces to the transducer using lines. A video camera was mounted beside the transducer (not indicated in the panels). An image of the tethered specimen seen from the transducer is shown between the two panels.

\section{TS Pattern Measurement in a Tank}

A sample fish for modeling was collected separately apart from the in situ TS measurement. Fishes including $D$. theta were collected in July 17,2006 at $41^{\circ} 52.5^{\prime} \mathrm{N}, 145^{\circ} 18.8^{\prime} \mathrm{E}$ using a MOHT net aboard the FRA research ship Hokko-maru (902 ton). The MOHT net was towed horizontally reaching a depth shallower than $22 \mathrm{~m}$ from the surface at night. Live myctophid fishes which were swimming in a container were selected, transferred into a 1 litter plastic bottle filled with sea water, and frozen. The specimens including one $D$. theta were gradually thawed by keeping the bottle in a refrigerator at $6^{\circ} \mathrm{C}$ for about three days before the TS measurement and soft X-ray observations.

Target strength of $D$. theta $(S L=6.53 \mathrm{~cm})$ was measured as a function of tilt angle in a seawater tank $(3.74(\mathrm{~L}) \times 2.24(\mathrm{~W}) \times$ 2.2(D) m, Fig. 5) in March 14, 2008. A thawed specimen was mounted sideways at $1 \mathrm{~m}$ depth as its dorsal aspect was facing to a side-looking transducer (KFC3000, Sonic Ltd., frequency: $120 \mathrm{kHz}$, beam width: $9.8^{\circ}$, pulse width: $0.6 \mathrm{~ms}$, ping rate: 1 $\mathrm{sec}$ ) by horizontally pulling a fishing line attached to the dorsal part of the specimen.

As the frequency $(120 \mathrm{kHz})$ was different from the one $(70$ $\mathrm{kHz}$ ) used for the in situ TS measurement, direct comparison of average TS at the same frequency is impossible. However, after confirming the validation of the theoretical model by the comparison of TS patterns between a measurement and model calculation at $120 \mathrm{kHz}$, predicted TS pattern at $70 \mathrm{kHz}$ would be valid for the average TS calculation.

The transducer was attached to a vertical bar that was connected to a horizontal arm rotated by a PC-controlled 
stepping motor (Fig. 5). The transducer was rotated around the specimen from $-30^{\circ}$ to $30^{\circ}$ (negative indicates head down, positive head up, and $0^{\circ}$ is normal incidence). The distance between the specimen and the transducer was $1.4 \mathrm{~m}$. Seawater in the tank was circulated and filtered to keep the seawater clean until just before the TS measurement. Temperature and salinity at a depth of $1 \mathrm{~m}$ were recorded every 1 second. Values of sound speed [13] and attenuation coefficient [8] were calculated based on the average values of temperature and salinity measured during the TS measurement. A 38.1mm-diameter tungsten carbide sphere was used for the calibration before and after the TS measurement. The average value of the transmitting and receiving factor, $T R$, of the echosounder was used to calculate target strengths using Eq. (1) by putting $D=0 \mathrm{~dB}$.

The echo signal with a carrier frequency taken from a buffer output of the receiver was monitored on a PC-controlled digital oscilloscope (LC334 or 9304AM; LeCroy Corporation, Chestnut Ridge, NY, USA). The oscilloscope sampled the signal at $10 \mathrm{MHz}$ using 8-bit analog to digital conversion by changing its vertical gain automatically according to the maximum echo signal level to maximize its vertical resolution effectively. The data acquisition sequence consisted of capturing 10 echoes including 9 shingle-shot echoes of separate pings and 1 averaged echo. The averaged echo, which was obtained by coherently averaging over 20 pings to improve the signal-to-noise ratio. These echoes were recorded in $1^{\circ}$ steps of the transducer rotation. Two scans under each condition were conducted; the first scan was for the measurement with specimen and the second without the specimen. Echoes from the specimen and unwanted echoes that were returned from walls and supporting structures were obtained in the first measurement, and only unwanted echoes were obtained from the second measurement.

Echoes from the specimen alone were extracted by coherently subtracting the unwanted echoes obtained in the second measurement from the echoes obtained in the first measurement for each transducer angle. A starting point corresponding to the distance from the transducer to the specimen was calculated using the correlation between subtracted echoes and a standard sphere echo. After the envelope of the subtracted echoes was detected using the Hilbert transform, the peak amplitude was found by searching from the leading edge of the pulse in the range corresponding to the pulse width. This series of signal processing steps was conducted automatically during post-processing.

\section{Model Calculations Based on the Swimbladder Shapes}

To confirm the swimbladder shape, the lateral and dorsal-aspect images of the swimbladder of $D$. theta used for TS measurement $(S L=6.53 \mathrm{~cm})$ were taken using a soft X-ray system (Protest-1000, Softex Ltd.) before and after the TS measurement. Fig. 6(a) shows a lateral optical image and Fig. 6(b) illustrates a swimbladder outline on a soft X-ray images of the fish we examined.

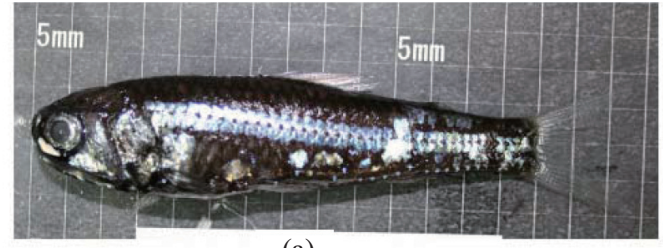

(a)

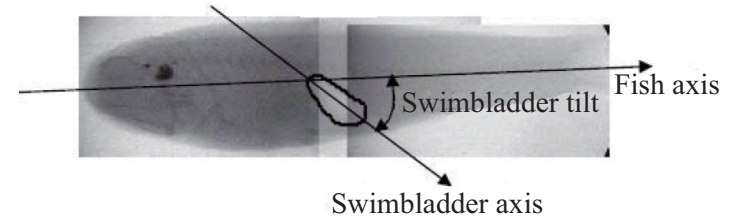

(b)

Fig. 6. (a) Optical and (b) soft X-ray images of the sample fish. Two arrows show fish axis and swimbladder axis, respectively. A white grid pattern equally spaced at $5 \mathrm{~mm}$ is laid behind the sample fish for scaling.

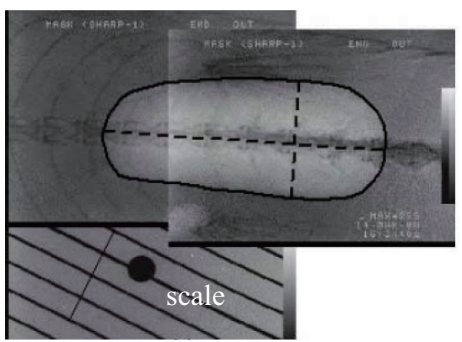

(a)

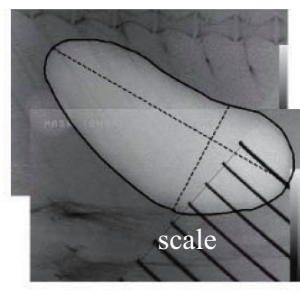

(b)
Fig. 7. (a) Magnified swimbladder images seen from dorsal and (b) lateral side taken before TS measurement. Swimbladder contours are traced by black lines. The dashed lines are the maximum and minimum distances. Scale of $1 \mathrm{~mm}$ space for each image is also shown with swimbaldder image.

Fig. 7 shows magnified dorsal and lateral images of the swimbladder, respectively. The swimbladder shape taken before the TS measurement was digitized using a software (Didger3, Golden software) and it was approximated as a prolate spheroid determined by two parameters (major and minor diameters). The swimbladder axis was defined as a line which maximizes a distance connected the two points on the digitized outlines of the lateral image (see Fig. 6). The distance was used as the major diameter (longer dashed line in Fig. 7 (a)). The minor diameter was obtained by the average of each maximum distance in the perpendicular direction to the swimbladder axis both in the lateral and dorsal images (Figs. 7(a), (b), shorter dashed lines). Swimbladder tilt angle was obtained from an angle between the fish axis and the swimbladder axis ; the fish axis was taken as it started from the tip of the fish upper jaw and ended at the center of the fork of the tail. A vacant prolate-spheroid modal series model [9] was used to calculate TSs as functions of frequency and tilt angle.

The relationship between standard length, $S L$, and average TS on tilt angle, $\langle T S>$, was shown as 


$$
<T S>=a \log S L+b
$$

where ' $a$ ' is a slope and ' $b$ ' is a reduced TS. Calculated TS pattern of a fish weighted by the assumed tilt-angle distribution, such as normal distribution, gives average TS $\langle T S>$. The reduced TS, ' $b$ ', can be derived from Eq. (2) assuming the slope, ' $a$ '.

To determine the upper TS threshold, expected maximum TS of $D$. theta was calculated based on the maximum $S L$ (7.47 $\mathrm{cm})$ sampled at MO.4, which was the largest among MO.4, 9, and 15 , assuming that the swimbladder size was proportional to the fish size. The ratios of $2 a / S L=0.160$ and $2 b / S L=0.071$ obtained from the modeled fish $(S L=6.53 \mathrm{~cm})$ give the major diameter $(2 a)$ of $1.19 \mathrm{~cm}$ and the minor one $(2 b)$ of $0.53 \mathrm{~cm}$ of $S L=7.47 \mathrm{~cm}$. As a result, the maximum TS was predicted as $-50.4 \mathrm{~dB}$. This is the ground of the upper TS threshold of $-50 \mathrm{~dB}$.

\section{RESULTS}

\section{In situ Measurement}

Average and the standard deviation of the pitch and roll angles of the J-QUEST $\chi$ were $0.8^{\circ}\left( \pm 1.1^{\circ}\right)$ and $2.2^{\circ}\left( \pm 0.9^{\circ}\right)$, respectively (positive pitch denotes J-QUEST $\chi$ head down, positive roll denotes left up).

Temperature and salinity at $150 \mathrm{~m}$ in depth were $3.45^{\circ} \mathrm{C}$ $\left( \pm 0.07^{\circ} \mathrm{C}\right)$ and $33.39 \mathrm{psu}( \pm 0.01 \mathrm{psu})$ respectively. These values gave an absorption coefficient of $19.62 \mathrm{~dB} / \mathrm{km}$ at $70 \mathrm{kHz}$, by Francois and Garrison [8] and sound speed of $1465.20 \mathrm{~m} / \mathrm{s}$ by Mackenzie [13], respectively. Sphere echoes $3.3 \mathrm{~m}$ below the transducer were seen in Fig. 4. Calculated sphere TS of -40.84 $\mathrm{dB}$ at this physical condition and measured amplitude gave $T R$ as $63.73 \mathrm{~dB}$ using Eq. (1).

In Fig. 3, echoes from J-QUEST $\chi$ continued from $150 \mathrm{~m}$ to $200 \mathrm{~m}$. It means that the echosounder installed on J-QUEST $\chi$ observed scatterers in the depth range from $150 \mathrm{~m}$ to $200 \mathrm{~m}$ with higher resolution. In Fig. 4, relatively strong echoes were seen near sphere echoes. These were identified as squids and walleye pollocks by the stereo-video camera observations under blue LED illuminations. Another strong echoes were also seen in the selected region for TS calculation (surrounded with frames in Fig. 4, between 20 to $50 \mathrm{~m}$ from the transducer of J-QUEST $\chi$ ).

Fig. 8 shows TS histograms of D. theta processed with different upper threshold values. The differences between them occur at greater or equal to $-49.5 \mathrm{~dB}$. Fig. 9 shows average TS values and the number of echoes at different upper-threshold value. Average TS values proportionally increase with the upper threshold values. Though the number of echoes also increases with the upper threshold values, a slightly large change happens at the threshold between -50 and $-49 \mathrm{~dB}$. Linear average TS values at the threshold of $-50,-49,-48$, and $-47 \mathrm{~dB}$ were averaged by weighting each number of echoes and its $10 \log$ value $(-55.76 \mathrm{~dB})$ was used as the average TS in situ.

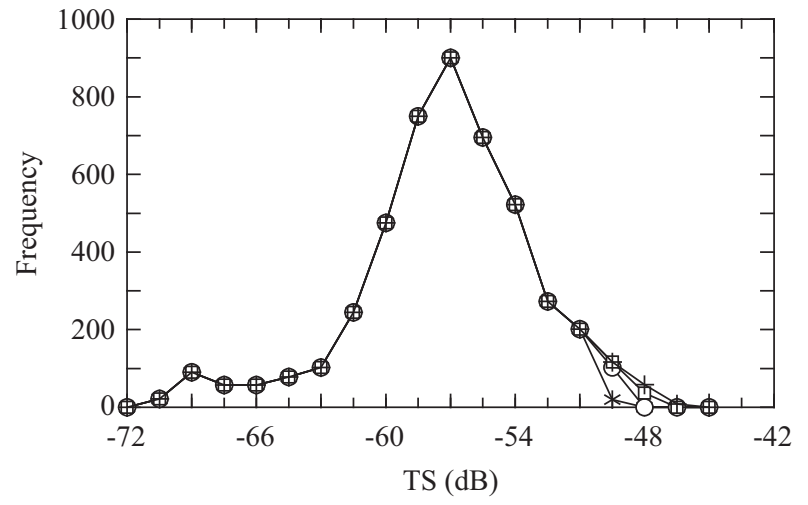

Fig. 8. Observed TS histograms of $D$. theta with four different upper TS thresholds $(-50,-49,-48$, and $-47 \mathrm{~dB})$. In this figure, stars, circles, squares, and crosses denote TS histograms at the threshold values of $-50,-49,-48$, and $-47 \mathrm{~dB}$, respectively.

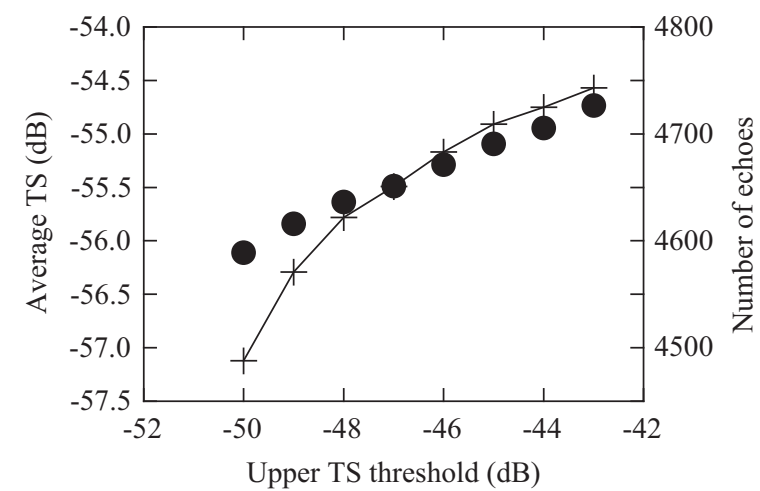

Fig. 9. Effect of the upper TS thresholds to measured average TS in situ (black circles) and number of echoes (crosses) analyzed.

\section{Frame Trawl Results}

Collected species were shown in Table 2. As results, 98.9\%$99.5 \%$ of the total catch (in individual number) was $D$. theta among three hauls. The average $S L$ and the standard deviation of $S L$ varied $5.45-5.55 \mathrm{~cm}$ and $0.37-0.43 \mathrm{~cm}$ as shown in Table 3 , respectively.

Reduced TS, $b=-70.6 \mathrm{~dB}$ was obtained using average TS, $<T S>=-55.8 \mathrm{~dB}$ and average standard length, $<L>=5.55 \mathrm{~cm}$, assuming $a=20$ in Eq. (2).

\section{Model Calculations Based on Soft X-ray Images of D. theta}

Swimbladder tilt angle shown in Fig. 6 was $35.6^{\circ}$. A large and small black circle like shape which are right side of the eye are otoliths. The black lines in the two images are traces of the contour of the swimbladder and the arrows show a fish axis and the swimbladder axis, respectively. Measured major diameter $(2 a)$ obtained from the lateral image was $1.04 \mathrm{~cm}$. Measured minor diameter $(2 b)$ obtained from the dorsal and lateral images were $0.456 \mathrm{~cm}$ and $0.472 \mathrm{~cm}$, respectively. As results, the swimbladder shape can be approximated as a prolate spheroid with a major diameter $(2 a)$ of $1.04 \mathrm{~cm}$ and a 
Table. 2. Collected species at St. MO.4, MO.9, and MO.15.

\begin{tabular}{|c|c|c|c|c|c|c|}
\hline \multirow{2}{*}{ Type of species } & \multicolumn{6}{|c|}{ Station } \\
\hline & MO4 individual & $\%$ & MO9 individual & $\%$ & MO15 individual & $\%$ \\
\hline Diaphus theta & 846 & $(99.5)$ & 175 & $(98.9)$ & 1379 & $(99.6)$ \\
\hline Stenobrachius leucopsarus & 0 & $(0.0)$ & 0 & $(0.0)$ & 3 & $(0.2)$ \\
\hline Symbolophorus californiensis & 0 & $(0.0)$ & 0 & $(0.0)$ & 1 & $(0.1)$ \\
\hline Stenobrachius sp. & 1 & $(0.1)$ & 0 & $(0.0)$ & 0 & $(0.0)$ \\
\hline Leuroglossus schmidti (jeuvenile) & 1 & $(0.1)$ & 2 & $(1.1)$ & 0 & $(0.0)$ \\
\hline Cololabis saira & 0 & $(0.0)$ & 0 & $(0.0)$ & 1 & $(0.1)$ \\
\hline Pleuronectiformes (lavae) & 2 & $(0.2)$ & 0 & $(0.0)$ & 0 & $(0.0)$ \\
\hline Total & 850 & $(100.0)$ & 177 & $(100.0)$ & 1384 & $(100.0)$ \\
\hline
\end{tabular}

Table. 3. Average, standard deviation, maximum, and minimum SL of D. theta at St. MO.4, MO.9, and MO.15.

\begin{tabular}{crcc}
\hline & \multicolumn{3}{c}{ Station } \\
\cline { 2 - 4 } & MO4 & MO9 & MO15 \\
\hline Number & 200 & 147 & 200 \\
Avg. (mm) & 55.5 & 55.4 & 54.5 \\
S.D. (mm) & 4.3 & 4.2 & 3.7 \\
Max (mm) & 74.7 & 66.2 & 66.6 \\
Min (mm) & 46.5 & 47.8 & 46.4 \\
\hline
\end{tabular}

minor one $(2 b)$ of $0.46 \mathrm{~cm}$, respectively. The aspect ratio $(b / a)$ between the major and the minor radius of the swimbladder was about 0.44 . For modeling the swimbladder, prolate spheroid mode series model [9] was chosen. Though the deformed cylinder model [33] could predict the TS pattern from a more complicated swimbladder shape, the model is only effective for low aspect ratios or elongated shapes and near broadside incidence. This is not for the present case.

\section{TS Pattern Measured in the Tank Experiment}

Fig. 10 compares measured $(120 \mathrm{kHz})$ and model based TS $(38,70,120,200 \mathrm{kHz})$ versus tilt angle for the fish we examined. A fish is horizontal when its tilt angle is $0^{\circ}$ and negative sign denotes head down, positive head up. As the tilt angle of the swimbladder axis relative to the fish axis was $35.6^{\circ}$, the peak TS shifted $35.6^{\circ}$ to the head down direction and the measurable range was $-30-+30^{\circ}$. As the result, the peak TS could not be detected in the present tank experiment.

\section{DISCUSSION}

The sample fish for modeling was taken in the nighttime trawl at depths shallower than $22 \mathrm{~m}$. Its standard length, swimbladder length, and swimbladder aspect ratio were measured as $6.53 \mathrm{~cm}, 1.04 \mathrm{~cm}$, and 0.44 , respectively. The swimbladder length is within the range of the reported value [30] but in the higher region. The swimbladder aspect ratio is also within the

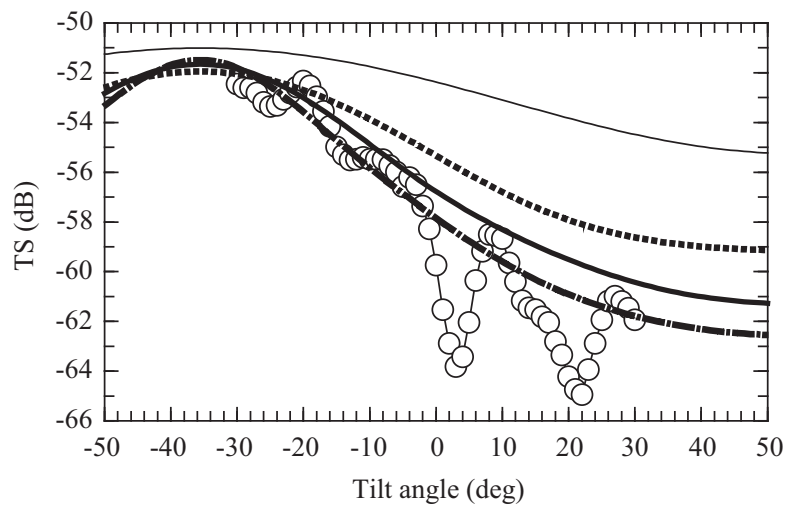

Fig. 10. Measured (white circles) at $120 \mathrm{kHz}$ and predicted TS at 120 $\mathrm{kHz}$ (black line), $200 \mathrm{kHz}$ (dashed-dotted line), $70 \mathrm{kHz}$, (dotted line), and $38 \mathrm{kHz}$ (thin black line) by PSM as a function of fish tilt angle. Predictions were shifted by $-35.6^{\circ}$.

range of the reported value of $0.42( \pm 0.13)$. These suggest that the observed swimbladder size used for modeling might be similar or slightly larger compared with the daytime steadstate size.

To confirm the validity of the in situ TS measurements, reduced target strengths were compared between the measurement and the theoretical predictions. Predicted TS pattern of the fish $(S L 6.53 \mathrm{~cm})$ at $70 \mathrm{kHz}$ was weighted by several tilt-angle distributions and averaged. Tilt-angle distributions were assumed as normal distributions with averages $(-20,-15$, $\left.-10,-9,-8,-7,-6,-5,-4,0,5,10,15,20^{\circ}\right)$ and standard deviations $\left(5,10,15,20,25,30^{\circ}\right)$ at 38 and $70 \mathrm{kHz}$. The slope of 18.5 was proposed by Yasuma et al. [29, 30]. Predicted reduced TSs by Eq. (2) with different slope values were shown in Fig. 11(a). The vertical bars indicate the ranges of reduced TS. Reduced TS at the slope of 20 obtained by measurement agreed well with predictions when the average tilt angle of fish was between $-7^{\circ}$ and $-5^{\circ}$, assuming the swimbladder tilt angle is $35.6^{\circ}$. Yasuma et al. [30], however, have reported that there were individual differences on the swimladder tilt angle. The average was $10.7^{\circ}\left( \pm 5.1^{\circ}, \mathrm{n}=174\right)$. The swimbladder tilt angle of $35.6^{\circ}$ measured in the present study was much larger than 


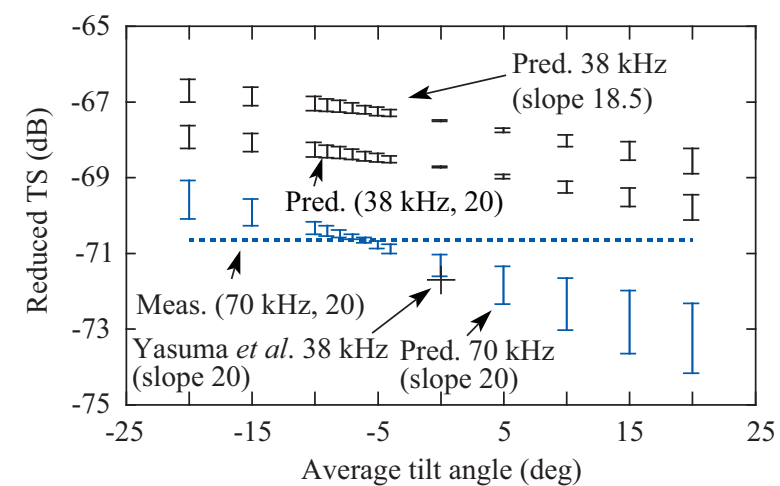

(a)

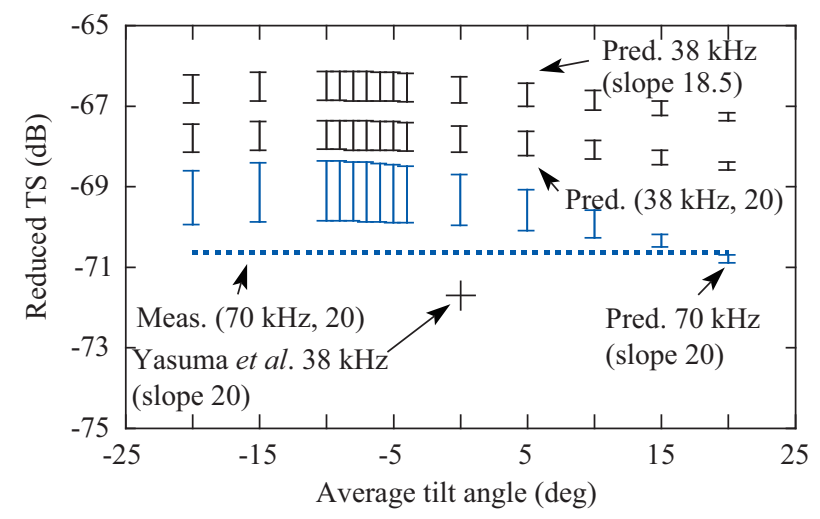

(b)

Fig. 11. Measured at $70 \mathrm{kHz}$ (dashed line) and predicted reduced TS at $38 \mathrm{kHz}, 70 \mathrm{kHz}$, and $120 \mathrm{kHz}$. The vertical bars show the maximum and the minimum values at the same average fish tilt angle $\left(-20,-15,-10,-9,-8,-7,-6,-5,-4,0,5,10,15,20^{\circ}\right)$ with different standard deviation $\left(5,10,15,20,25,30^{\circ}\right)$. (a) swimbladder tiltangle $=35.6^{\circ}$ and $(\mathrm{b})$ swimbladder tilt-angle $=10.7^{\circ}$.

their results. The swimbladder tilt angle affects average TS values weighed by fish tilt-angle distributions. If the swimbladder angle was $10.7^{\circ}$, predicted reduced TSs become more flat for the average tilt angle and the variation of reduced TS at each average tilt angle becomes large at angles below 5 degrees (Fig. 11(b)). Expected average tilt angle would shift between $+15 \sim+20^{\circ}$ where measured TS at $70 \mathrm{kHz}$ coincides with predicted values at $70 \mathrm{kHz}$.

Yasuma et al. [30] have also shown the relationship between SL and $<\mathrm{TS}>$ as $<\mathrm{TS}>=18.5 \log$ SL-71.7 at $38 \mathrm{kHz}$. If we choose the slope of 18.5 for the model prediction at $38 \mathrm{kHz}$ reduced TS become $-67.3 \sim-67.1 \mathrm{~dB}$ at the average tilt angle of $-6^{\circ}$ where predicted and measured reduced TS at $70 \mathrm{kHz}$ agreed well. Though it is approximately $4 \mathrm{~dB}$ higher than -71.7 $\mathrm{dB}$ by Yasuma et al. [30], it is still within their predicted range (-86.6 -65.2 dB). Barham [1] has reported that a large number of myctophid fish swims in close to the horizontal position in the daytime by the visual observation using a submersible. Direct measurements of the tilt angle distribution will be needed as future study.

Benoit-Bird and $\mathrm{Wu}[3]$ have reported $T S=20 \log S L-58.8$ at $200 \mathrm{kHz}$ for 8 species of myctophids by ex situ TS measure- ment in a tank $(\mathrm{n}=56)$. Their TS is not a averaged TS on tilt-angle distribution but close to the normal incidence to the dorsal side of fish. Though we can not compare directly with the present results, we may compare their result with the reduced TS on the maximum TS in the predicted TS pattern at $200 \mathrm{kHz}$. Predicted maximum TS of $6.53 \mathrm{~cm} \mathrm{D.} \mathrm{theta} \mathrm{in} \mathrm{the}$ present study was $-51.5 \mathrm{~dB}$ as shown in Fig. 10. Reduced maximum TS becomes $-67.80 \mathrm{~dB}$, assuming $a=20$ in Eq. (2). Their result is $9 \mathrm{~dB}$ higher than the predicted maximum reduced TS at $200 \mathrm{kHz}$.

Net sampling is one of the error sources to obtain representative length distribution and a suitable gear for species is essential to minimize the error. Yamamura [27] conducted an inter-calibration between four different net gears and investigated fishing efficiency of each gear compared to a mid-water otter trawl net $\left(900 \mathrm{~m}^{2}, 3 \mathrm{kt}\right)$ at close location where the present study was conducted. Fishing efficiencies were estimated for two different size groups. One was less than $40 \mathrm{~mm}$ and the other was larger than $40 \mathrm{~mm}$. The results were that $82 \%$ of the total catch in individual number was D. theta and MOHT net $\left(5 \mathrm{~m}^{2}\right.$, mesh size $\left.9 \mathrm{~mm}, 3 \mathrm{kt}\right)$ showed the highest fishing efficiency for micronektonic fishes for both of the size group among four gears including the mid-water trawl net. The frame trawl used in this study was the same type and the only difference was the mesh size (4 $\mathrm{mm}$ in this study).

Stenobrachius leucopsarus and Sybolophorus californiensis were collected at MO.15. The number of each species is very small, compared to the total catch as seen in Table 2 . In addition, $S$. leucopsarus is a swimbladderless fish [32]. The effects of two species could be neglected.

Evidently, we can see several echoes stronger than other echoes in the TS observed layer in Fig. 4 (surrounded with frames). These were presumably considered to be echoes from squids or walleye pollock which were observed by J-QUEST $\chi$ and also captured at MO.2. Reduced TS of walleye Pollock at $38 \mathrm{kHz}$ has been reported as $-66.0 \mathrm{~dB}$ [7]. Both the fish size and reduced TS were apparently larger than $D$. theta. To remove the unwanted large echoes, we changed the upper threshold values from -50 to $-47 \mathrm{~dB}$ and investigated the effect to the average TS (Fig. 9). The values of $50 \mathrm{~dB}$ came from the maximum TS of $D$. theta with $S L=7.47 \mathrm{~cm}$ which was the maximum SL among 3 hauls (MO.4, 9, 15) and $-47 \mathrm{~dB}$ came from the maximum $\mathrm{TS}+3 \mathrm{~dB}$ allowance corresponding to $+3.08 \mathrm{~cm}$ allowance in $S L$. Linear average TS values at the threshold of $-50,-49,-48$, and $-47 \mathrm{~dB}$ were averaged by weighting each number of echoes and its $10 \log$ value was used as the average TS in situ. Obtained average TS became -55.8 $\mathrm{dB}$. It was $0.35 \mathrm{~dB}$ larger than the average TS at $-50 \mathrm{~dB}$ threshold and $0.27 \mathrm{~dB}$ smaller then the one at $-47 \mathrm{~dB}$ threshold. The variation was small. Though the upper threshold method is not a perfect method but it can only mitigate the positive bias of the estimated average TS, it was effective in the present study.

McClatchie et al. [15] have pointed out that TS could not normalized by the square of the length as the swimbladder 
length does not always increase with fish length in terms of the deep water fish. Yasuma et al. [30], however, have shown that linear TS of D.theta is nearly proportional to the square of the length and swimbladderless fish appears when a fish is larger than $7.8 \mathrm{~cm}$ in SL which was not sampled in this study. This indicates that there were few which did not have swimbladder.

As we could not measure in situ TS at different fish length, there is no evidence to reject $20 \log$ model in this stage. Further in situ TS measurements could resolve this issue.

\section{CONCLUSION}

In situ TS measurement for D. theta distributed in the slope region off the east of Hokkaido was conducted using J-QUEST $\chi$ and average TS of $-55.8 \mathrm{~dB}$ was obtained. A frame trawl sampling for $D$. theta showed an average standard length of $5.55 \pm 0.43 \mathrm{~cm}, \mathrm{n}=200$. From these data the dorsal aspect TS at $70 \mathrm{kHz}$ was related to the length: TS $=20 \log$ (standard length in $\mathrm{cm}$ ) -70.6. Dorsal aspect TS measurement for defrosted $D$. theta was conducted by rotating a $120 \mathrm{kHz}$ transducer around the specimen and compared with model calculation based on the swimbladder shape of the specimen. Both agreed well. Theoretical TS calculation showed that the reduced TS obtained by the in situ measurement was reasonable.

\section{ACKNOWLEDGMENTS}

We thank associate professor, Kazuhiko Anraku (Kagoshima university), Tomoki Ogawa, and Junya Shigeno for their various field assistance. We thank crew of RV "Wakataka-Maru" for their dedicated assistance. Anonymous referees and the guest editor, Dr. Masahiko Furusawa greatly improved this manuscript.

\section{REFERENCES}

1. Barham, E. G., "Deep scattering layer migration and composition, observations from diving saucer," Science, Vol. 151, pp. 1399-1403 (1966).

2. Beamish, R. J., Leask, K. D., Ivanov, O. A., Balanov, A. A., Orlov, A. A., and Sinclair, B., "The ecology, distribution, and abundance of midwater fishes of the Subarctic Pacific gyres," Progress in Oceanography, Vol. 43, pp. 399-442 (1999).

3. Benoit-Bird, K. J. and Au, W. W. L., "Target strength measurements of Hawaiian mesopelagic boundary community animals," Journal of the Acoustical Society of America, Vol. 110, pp. 812-819 (2001).

4. Brodeur, R. and Yamamura, O. (Eds.), "Micronekton of the North Pacific,” PICES Scientific Report, Vol. 30, PICES, Sidney, Canada (2005).

5. Foote, K. G.., "Importance of the swimbladder in acoustic scattering by fish: a comparison of gadoid and mackerel target strength," Journal of the Acoustical Society of America, Vol. 67, pp. 2084-2089 (1980).

6. Foote, K. G., "Fish target strengths for use in echo integrator surveys," Journal of the Acoustic Society of America, Vol. 82, pp. 981-987 (1987).

7. Foote, K. G. and Traynor, J. J., “ A comparison of walleye pollock target strength estimates derived from in situ measurements and calculations based on swimbladder form," Journal of Acoustic Society of America, Vol. 83, pp. 9-17 (1988).

8. Francois, R. E. and Garrison, G. R., "Sound absorption based on ocean measurements. Part II: Boric acid contribution and equation for total absorption," Journal of the Acoustic Society of America, Vol. 72, pp.
1879-1890 (1982).

9. Furusawa, M., "Prolate-spheroid models for predicting general trends of fish target strength," Journal of the Acoustical Society of Japan, Vol. 9, pp. 13-24 (1988).

10. Furusawa, M. and Amakasu, K., "The analysis of echotrace obtained by a split-beam echosounder to observe tit-angle dependence of fish target strength in situ," ICES Journal of Marine Science, Vol. 67, pp. 215-230 (2010).

11. GjØsaeter, J. and Kawaguchi, K., "A review of the world resources of mesopelagic fish," FAO Fisheries Technical Paper, FAO, Rome, Italy (1980).

12. Horne, J. K., Sawada, K., Abe, K., Kreisberg, R. B., Barbee, B. H., and Sadayasu, K., "Swimbladders under pressure: anatomical and acustic responses by walleye Pollock," ICES Journal of Marine Science, Vol. 66, pp. 1162-1168 (2009).

13. Mackenzie, K. V., "Nine term equation for sound speed in the oceans," Journal of the Acoustic Society of America, Vol. 70, pp. 807-812 (1981).

14. MacLennan, D. and Simmonds, R. J., Fisheries Acoustics, Chapman and Hall, London, U.K. (1992).

15. McClatchie, S., Macaulay, G. J., and Coombs, R., "A requiem for the use of $20 \log 10$ Length for acoustic target strength with special reference to deep-sea fishes," ICES Journal of Marine Science, Vol. 60, pp. 419-428 (2003).

16. Ohizumi, H., Kuramochi, T., Kubodera, T., Yoshioka, M., and Miyazaki, N., "Feeding habits of Dall's porpoises (Phocoenoides dalli) in the subarctic North Pacific and the Bering Sea basin and the impact of predation on mesopelagic micronekton," Deep-Sea Research I, Vol. 50, pp. 593-610 (2003).

17. Oozeki, Y., Hu, F., Kubota, H., Sugisaki, H., and Kimura, R., "Newly designed quantitative frame trawl for sampling larval and juvenile pelagic fish," Fisheries Science, Vol. 70, pp. 223-232 (2004).

18. Sawada, K., Furusawa, M., and Williamson, N. J., "Conditions for the precise measurement of fish target strength in situ," Journal of the Marine Acoustics Society of Japan, Vol. 20, pp. $73-79$ (1993).

19. Sawada, K., Sato, T., Abe, K., Kuratsu, K., Amakasu, K., and Matsuura, T., "Comparison of two split-beam transducers different backing structures developed for deep sea research," Proceedings of the Marine Acoustical Society of Japan, Tokyo, Japan, pp. 11-14 (2008). (in Japanese)

20. Sawada, K., Takahashi, H., Abe, K., Ichii, T., Watanabe, K., and Takao, Y., "Target strength, length, tilt-angle measurements of Pacific saury (Cololabis saira) and Japanese anchovy (Engraulis japonicus) using an acoustic-optical system," ICES Journal of Marine Science, Vol. 66, pp. 1212-1218 (2009).

21. Sawada, K., Takahashi, H., Takao, Y., Watanabe, K., Horne, J. K., McClatchie, S., and Abe, K., "Development of Acoustic-Optical System to estimate Target-Strengths and Tilt Angles from Fish Aggregations," Oceans04/ Tech-Ocean04 Proceedings, Vol. 1, pp. 395-400 (2004).

22. Sawada, K., Uchikawa, K., Sugisaki, H., Matuura, T., Amakasu, K., and K. Abe, "Target strength measurements of Diaphus theta in situ off the east coast of Hokkaido using a newly designed acoustic-optical observing system (J-QUEST $\chi$ ), Proceedings of 21 st Ocean Engineering Symposium, Tokyo, Japan, pp. 6-7 (2009). (in Japanese)

23. Takahashi, H., Sawada, K., Takao, Y., and Abe, K., "Inspection of the three dimensional measurement accuracy of J-QUEST Stereo TV-camera system," Technical Report of National Research Institute of Fisheries Engineering, Vol. 27, pp. 81-92 (2005). (in Japanese)

24. Takahashi, H., Sawada, K., Watanabe, K., Horne, J. K., McClatchie, S., Takao, Y., and Abe, K., "Development of a stereo TV camera to complement fish school measurement by a quantitative echo sounder," Oceans04/Tech-Ocean04 Proceedings, Vol. 1, pp. 409-414 (2004).

25. Traynor, J. J., "Target-strength measurements of walleye pollock (Theragra chalcogramma) and Pacific whiting (Merluccius productus)," ICES Journal of Marine Science, Vol. 53, pp. 253-258 (1996).

26. Watanabe, H., Moku, M., Kawaguchi, K., Ishimaru, K., and Ohono, A., "Diel vertical migration of myctophid fishes (Family Myctophidae) in the 
transitional waters of the western North Pacific," Fisheries Oceanography, Vol. 8, pp. 115-127 (1999).

27. Yamamura, O., "Comparison of sampling gears for micronekton in PICES-MIE,” Nippon Suisan Gakkaishi, Vol. 73, pp. 931-932 (2007). (in Japanese)

28. Yamamura, O., Honda, S., Shida, O., and Hamatsu, T., "Diets of walleye pollock Theragra chalcogramma in the Doto area, northern Japan: ontogenetic and seasonal variations," Marine Ecology Progress Series, Vol. 238, pp. 187-198 (2002).

29. Yasuma, H., Oshima, T., Honda, S., Miyashita, K., and Aoki, I., "Acoustic biomass estimate of California headlightfish, Diaphus theta, off eastern Hokkaido, Japan,” Nippon Suisan Gakkaishi, Vol. 76, pp. 362-369 (2010)

30. Yasuma, H., Sawada, K., Miyashita, K., and Aoki, I., "Swimbladder morphology and target strength of myctophid fishes in the northwestern
Pacific," Journal of the Marine Acoustics Society of Japan, Vol. 35, pp. 17-28 (2008). (in Japanese)

31. Yasuma, H., Sawada, K., Oshima, T., Miyashita, K., and Aoki, I., "Target strength of mesopelagic lanternfishes (family Myctophidae) based on swimbladder morphology," Ices Journal of Marine Science, Vol. 60, pp. 584-591 (2003)

32. Yasuma, H., Takao, Y., Sawada, K., Miyashita, K., and Aoki, I., “Target strength of the lanternfish, Stenobrachius leucopsarus (family Myctophidae), a fish without an airbladder, measured in the Bering Sea," ICES Journal of Marine Science, Vol. 63, pp. 683-692 (2006).

33. Ye, Z., Hoskinson, E., Dewey, R. K., Ding, L., and Farmer, D., "A method for acoustic scattering by slender bodies. I. Theory and verification," Journal of the Acoustical Society of America, Vol. 102, pp. 1964-1976 (1997). 